Fecha de entrega: 22 de mayo de 2010

Fecha de aprobación: 30 de junio de 2010

\title{
DERECHOS HUMANOS COMO DERECHOS DEL OTRO EN LÉVINAS*
}

\section{HUMAN RIGHTS AS RIGHTS OF THE OTHER IN LÉVINAS}

\author{
Edgar Antonio López ${ }^{* *}$
}

\section{Resumen}

La formulación tradicional de los derechos humanos se basa en la libertad y la igualdad, pero Emmanuel Lévinas hace de la diferencia absoluta la fuente y el fundamento de tales derechos. Los Derechos Humanos aparecen entonces como los derechos del Otro y extienden el alcance de la responsabilidad hasta comprometer la propia libertad. La primera parte de este trabajo muestra cómo la preocupación por los derechos humanos fue una constante en la existencia y el pensamiento de Lévinas. La segunda parte está dedicada a exponer la fundamentación levinasiana de los derechos humanos con base en la illeidad.

\section{Palabras clave}

Derechos humanos, Illeidad, Otro, ontología, ética, responsabilidad, dignidad humana.

\begin{abstract}
Traditional formulation of Human Rights is based on freedom and equality, but Emmnauel Lévinas makes absolute difference the source and the ground of those rights. Human Rights appear as the Rights of the Other and extend responsibility so as to endanger own freedom. The first part of this writing shows how concern for Human Rights was constant in Lévinas existence and though. The second part is devoted to explaining levinasian fundamentals of Human Rights based on illeity.
\end{abstract}

\section{Key words}

Human Rights, Illeity, Other, ontology, ethics, responsibility, human dignity.

Artículo de investigación para este número monográfico.

** Filósofo de la Pontificia Universidad Urbaniana. Licenciado en Filosofía e Historia de la Universidad Santo Tomás. Magíster en Filosofía de la Universidad Nacional de Colombia. Magíster y Doctor en Teología de la Pontificia Universidad Javeriana. Profesor Asociado del Departamento de Teología de la Universidad Javeriana. Profesor Titular del Departamento de Educación de la Universidad Militar Nueva Granada. 


\section{Emmanuel Lévinas y los derechos humanos}

La vida personal y académica del filósofo lituano-francés Emmanuel Lévinas estuvo estrechamente ligada a una preocupación existencial por los derechos humanos. Durante la Primera Guerra Mundial del siglo $\mathrm{XX}$, siendo un niño todavía, tuvo que vivir el exilio en Ucrania, donde su familia presenció los acontecimientos de la revolución rusa. Después de haber estudiado filosofía en Estrasburgo y en Friburgo obtuvo la nacionalidad francesa. En Francia divulgó el pensamiento de Husserl y de Heidegger, pero dedicó la mayor parte de su tiempo a la obra escolar de la Alianza Israelita Universal, institución dedicada a promover los derechos humanos de la población judía.

El ascenso del nacionalsocialismo señaló un giro radical en el pensamiento de Emmanuel Lévinas, pues le condujo a asumir una actitud crítica ante la tradición filosófica occidental, una tradición derivada de la afirmación del ser bajo la forma de ontología. Tal afirmación del ser se expresaba históricamente como afirmación de una manera de ser que, fundamentada en la sangre y en la tierra, devenía en racismo. La crítica de la ontología tradicional por sus vínculos con la dominación política sería la fuente de inspiración para su obra filosófica posterior: "La filosofía occidental ha sido con más frecuencia una ontología: una reducción de lo Otro a lo Mismo" (Lévinas, 1961, p. 33).

La respuesta del filósofo a la persecución desencadenada por el antisemitismo en Europa consistió en volver a las fuentes judías para criticar los desarrollos violentos del proyecto filosófico que atraviesan toda la historia occidental. "Si el antisemitismo se muestra cómplice del ontologismo de Occidente, la apuesta por un discurso no ontológico habrá de desarrollarse paralelamente a la recuperación de la tradición perseguida" (Sucasas,
1998, p. 19). Como filósofo y como judío, Lévinas acudió a la tradición sapiencial hebrea para hacerle frente a la ontología cómplice de la violencia. Su resistencia intelectual estaría animada al principio por la lectura de $L a E s$ trella de la Redención, de Franz Rosenzweig, y se hará pronto manifiesta como crítica al nazismo en Algunas reflexiones sobre la filosofia del hitlerismo (1934) y en otros ensayos dirigidos contra el totalitarismo. Después de la Segunda Guerra Mundial del siglo XX, Lévinas profundizaría sus estudios sobre el judaísmo bajo la dirección del Sr. Chouchani, maestro de exégesis talmúdica, hallando en esta tradición valiosos elementos para su reflexión teológica y filosófica en torno al carácter infinito del ser humano.

Durante esta guerra, en su calidad de ciudadano francés, se había incorporado al ejército como intérprete, dado su manejo de las lenguas rusa y alemana, pero en 1939 fue hecho prisionero y llevado a Alemania. $\mathrm{Su}$ condición de judío lo habría conducido a la muerte, pero su condición de prisionero de guerra francés le salvó de compartir el trágico destino de su familia, exterminada por los nazis. Durante su cautiverio pudo alternar el trabajo físico con el trabajo intelectual y escribió De l'existence à l'existant, obra publicada en 1947.

Haberse convertido en sobreviviente del holocausto marcó definitivamente la vida de Emmanuel Lévinas. Esto es patente tanto en su producción filosófica, crítica de la ontología tradicional, como en sus convicciones políticas, enemigas de toda forma de segregación, persecución racial y violencia. Si después de la guerra Lévinas había vuelto a la libertad, jamás volvería a pisar suelo alemán y tampoco volvería intelectualmente al curso de la tradición filosófica occidental. Su empresa sería la de proponer otra manera diferente a la del ser, sentido en que debe ser comprendido el título de su obra maestra $D e$ 
otro modo que ser, o más allá de la esencia (1974).

El estudio de la condición humana había sido para Lévinas una tarea fascinante desde su infancia, en la que gracias a su padre tuvo un contacto estrecho con la literatura universal. Esta inquietud lo acompañaría durante el desarrollo de sus estudios filosóficos, especialmente en Friburgo, donde tuvo la experiencia intelectual de encontrarse con dos titanes de la filosofía del siglo XX: "La gran cosa que encontré fue el modo en que la vía de Husserl era prolongada y transfigurada por Heidegger. Por hablar un lenguaje turístico, tuve la impresión de haberme dirigido a Husserl y haber encontrado a Heidegger" (Sucasas, 1998, p. 16).

En su tesis doctoral, titulada Teoría de la intuición en la fenomenología de Husserl (1930), Lévinas había evidenciado la utilidad del pensamiento heideggeriano para establecer los límites de la fenomenología husserliana. En efecto, Heidegger había devuelto al ser su carácter dinámico de verbo, después de muchos siglos en que la tradición occidental lo había encerrado en la quietud del sustantivo. Sin embargo, en el discurso de Heidegger el ser humano pasaba progresivamente a un lugar más bien marginal, mientras para el pensamiento de Lévinas cada vez lo humano se hacía más importante.

Mientras Heidegger, preocupado por erradicar el privilegio de la subjetividad todavía vigente en el discurso de Sein und Zeit, propone una cierta puesta entre paréntesis del ente-Dasein humano-para celebrar el acontecer del ser, Lévinas ve en la tachadura del ser puro, de su acontecer anónimo e impersonal, el requisito necesario para la emergencia de un ente personal, de un existente humano (Sucasas, 1998, p. 18).
Heidegger había despertado en su discípulo lituano sentimientos de admiración por su obra Ser y tiempo, pero los trabajos ulteriores de este gran filósofo mostraban que había subordinado el ser humano al Ser. Al desencanto que esta marginación de los humanos produjo en Lévinas, hay que sumar el profundo rechazo que le causó el compromiso de Heidegger con el nacionalsocialismo al aceptar la rectoría de la Universidad de Friburgo en 1933:

La noticia hizo que se tambaleara mi firme convicción de que existe una distancia insalvable y eterna entre el odio criminal y enloquecido que proclama el mal desde las páginas de Mein Kampf, y la agudeza intelectual $\mathrm{y}$ el virtuosismo extremadamente analítico de Ser y tiempo (Sucasas, 2004, p. 24).

La misma ontología, con la que Heidegger había sacado a la luz la pregunta por el ser para refundar la metafísica, había devenido en filosofía de la identidad que suprime las diferencias.

Filosofía del poder, la ontología como filosofía primera que no pone en cuestión el Mismo, es una filosofía de la injusticia. La ontología heideggeriana que subordina el encuentro con el Otro a la relación con el ser en general... permanece en la obediencia de lo anónimo y conduce, fatalmente, a otro poder, a la dominación imperialista, a la tiranía" (Lévinas, 1961, p. 38).

Proponer una nueva manera, diferente a la de ser, sobre la que se ha constituido la ontología tradicional, no es tarea fácil, y en ello estriba la genialidad de Lévinas, quien debió hacerlo, empleando un lenguaje adecuado al modo del ser. La fuerza de la crítica levinasiana 
al pensamiento tradicional de Occidente es comparable al vitalismo de Friedrich Nietzsche, aunque ésta vaya en dirección contraria (López, 2002).

La crítica de Nietzsche puede ser considerada como la más contundente que haya conocido el pensamiento occidental, pero propone una afirmación del ser sin precedentes. Lévinas, en cambio, propone el aplazamiento de tal afirmación como único medio para que se dé la relación ética que excluye toda violencia. "En la relación ética se da una tensión contrapuesta a la ontología del verbo ser... la óntica está referida a una tensión que corrige la obstinación del ser-en-sí" (López, 2004, p. 89). En el pensamiento divergente de estos dos geniales críticos de Occidente, la violencia de una tradición que extingue la vida ha quedado en evidencia.

La obra levinasiana es un legado que la filosofía debe hacer suyo en contextos en que muchos seres humanos se afirman sobre otros y se entregan a la guerra justificando la exterminación de otros seres en aras de un futuro mejor, del cual sólo se tiene como evidencia la sangre, la muerte, el dolor y el desconsuelo. Muchos seres humanos, y no humanos también, necesitan que pospongamos la afirmación de nuestro propio ser para que puedan seguir siendo y para permitirnos existir como responsabilidad. Esa es la relevancia que tiene hoy el pensamiento de Emmanuel Lévinas para la reflexión en torno a los derechos humanos.

\section{Derechos humanos y derechos del Otro}

Nunca es fácil hablar o escribir sobre el pensamiento de Lévinas, pues cada palabra pronunciada o escrita amenaza con hacerse presente la violenta afirmación del ser. Nuestro lenguaje corresponde a la ontología en que la subjetividad aparece como principio de la reflexión y, como portadora de la primera palabra, asimila las diferencias de su entorno a sus propios esquemas. El horizonte del pensamiento levinasiano es otro, pues en él no se parte de la subjetividad sino de la illeidad, que no ha de comprenderse como alteridad de una subjetividad que se halla ante otra, sino como la aparición del rostro del Otro ante la propia mirada.

En la filosofía levinasiana existe un problema para hablar de los derechos humanos, pues para el filósofo lituano-francés la noción de humanidad no coincide con la de género humano. De otro modo no sería posible en su pensamiento la illeidad como unicidad (Purcell, 1996). "Unicidad que no se olvida bajo todas las constricciones del Ser, de la Historia y de las formas lógicas que la limitan" (Lévinas, 1987, p. 160).

La dignidad de cada ser humano no tiene que ver con su pertenencia a un género sino con su absoluta singularidad en él. "Alteridad de lo único y de lo incomparable, a causa de la pertenencia de cada uno al género humano, la cual, ipso facto y paradójicamente, se anularía, precisamente para dejar a cada hombre único en su género" (Lévinas, 1987, p. 160). El carácter singular, incomparable e irreductible de cada ser humano, su illeidad, es fuente de la plena dignidad de toda la humanidad que desde él o desde ella interpela a todo yo.

En la modernidad el discurso de los derechos humanos, basado en las nociones de libertad y de igualdad, pretendió abarcar a la humanidad toda, cuyos miembros supuestamente comparten una misma dignidad. Para Lévinas, en cambio, cada uno, cada Otro, es portador de toda la dignidad de la humanidad. No se trata de una dignidad individual que lo hace parte de una clase o de un género sino de la plenitud de la humanidad presente en cada Otro. 
Mantenerse en la justicia, en la norma de la pura medida $-\mathrm{o}$ moderación- entre términos que se excluyen, sería todavía asimilar el encuentro entre los miembros del género humano al encuentro entre individuos de una clase lógica que no significan el uno para el otro sino negación, agregaciones o indiferencia (Lévinas, 1987, p. 168).

Desde la singularidad, propuesta por Lévinas como illeidad, es mejor entonces referirse a los derechos del Otro, para pensar en el alcance y el fundamento de los llamados derechos humanos. La óptica levinasiana impone la necesidad de pensar en los derechos del Otro a partir de la diferencia, no de la igualdad. De ordinario, se piensa en los derechos humanos a partir de la dignidad que, se supone, reina entre los seres humanos en virtud de una afirmación ontológica del ser que los hace iguales. No obstante, para Lévinas los derechos humanos "manifiestan la unicidad o el absoluto de la persona a pesar de su pertenencia al género humano o a causa de esa pertenencia" (Lévinas, 1987, pp.160-161). En esto consiste la illeidad, es decir la unicidad inconmensurable del Otro.

Es la diferencia y no la igualdad la que posibilita desde la perspectiva levinasiana una preocupación auténtica por aquello que se identifica como derecho del Otro. En cambio, ver al Otro como semejante atenúa la responsabilidad, pues "la preocupación por los semejantes siempre será moderada en la medida en que estos sean semejantes" (López, 2005 , p. 82). Es así como mientras el discurso tradicional de los derechos humanos remite a la fraternidad universal entre iguales, la visión levinasiana de los derechos del Otro comporta en cambio la necesidad de una "fraternidad dentro de la extrema separación" (Lévinas, 1998, p. 98). Se trata de una condición que aleja a las personas en la infinita diferencia pero que las aproxima en la inexorable responsabilidad, comprometiendo a cada uno con los derechos de cada Otro y también con la vulneración de los derechos de alguien que aquel Otro pueda operar en el mundo.

La responsabilidad para con el Otro es infinita y suspende la propia libertad, pues yo soy responsable de todo el mal que hay en el mundo, del mal que el Otro padece, pero también del mal que el Otro causa. Los derechos del Otro son una exigencia que extiende las fronteras de la responsabilidad más allá de las propias intenciones y de las acciones del yo, sumiéndolo en una culpabilidad que sólo deja abierta la posibilidad de la subjetividad como responsabilidad. Ese es el horizonte en el que aparecen ante el yo los derechos del Otro, ampliamente denominados como derechos humanos.

Acerca de los derechos humanos, afirma Lévinas, que para la conciencia contemporánea son "más legítimos que cualquier legislación, más justos que cualquier justificación" (Lévinas, 1987, p. 159). En esto consiste su naturaleza a priori, pero esto no debe ser entendido como a priori en el sentido kantiano. Los derechos del Otro no son un legado de la humanidad a los individuos en los que ella misma perdura, tampoco un reconocimiento de la sociedad a quien los merezca por su empeño o por su carácter virtuoso. Los derechos del Otro son derechos a priori porque son "anteriores a toda concesión: a toda tradición, a toda jurisprudencia, a toda distribución de privilegios, de dignidades o de títulos, a toda consagración por una voluntad que se pretendiera abusivamente razón" (Lévinas, 1987, pp. 159-160). Esta precedencia de los derechos a toda declaración les hace irrevocables, pues hunden sus raíces en la illeidad, unicidad irreductible que hace de cada Otro un otro único, infinitamente distinto del yo. 
Lévinas constata que a partir de los mandatos bíblicos "Nunca matarás" y "Amarás al extranjero", pasando por un largo proceso histórico, Occidente ha llegado a reconocer unos derechos universales como principios fundamentales de la legislación y del orden social. Es así como todo ser humano, por su condición debe tener un lugar especial en el orden del ser, el lugar que corresponde a sus derechos.

El hombre en cuanto hombre tendría derecho a un lugar excepcional en el ser... el derecho a una independencia o a la libertad de cada uno reconocida por cada uno... derecho a una posición a salvo del orden inmediato de las necesidades inscritas en las leyes naturales que rigen las cosas... lugar excepcional, derecho al querer libre, garantizado y protegido en las leyes promulgadas por el hombre (Lévinas, 1985, p. 215).

Tales derechos protegen al ser humano de los peligros que comporta la afirmación de los demás seres vivos en la naturaleza y en la sociedad, tratando de dejar a salvo la voluntad libre del hombre. Puede que estos derechos no hagan desaparecer "los rigores últimos de lo inhumano en el ser que, por la firmeza insuperable de las costuras que constituyen su tejido,... contraría y limita siempre la voluntad libre del hombre" (Lévinas, 1985, p. 216), pero posibilitan en su conjunto el perfeccionamiento de la libertad.

Desde la visión levinasiana el reconocimiento de los derechos del Otro sólo puede darse en el marco de una relación en la que el Otro no sea reducido al Mismo por el yo, es decir en el marco de la relación ética, relación fundante de toda otra relación auténticamente humana, de toda relación cara a cara entre dos, una relación que remite a la humanidad entera. El encuentro con el Otro es el encuentro con la humanidad toda, pues la universalidad que en el discurso moderno apunta a la igualdad, en la perspectiva aquí descrita señala hacia la illeidad como unicidad, "unicidad, más allá de la individualidad de individuos múltiples en su género" (Lévinas, 1987, p. 160).

Es así como el concepto de universalidad que sirve de fundamento tradicional a los derechos humanos, haciendo a los individuos idénticos los unos a los otros, aparece en los derechos del Otro como la idea de lo universal, que no se agota en lo individual y que impide encerrar al Otro en la identidad y en el concepto, pero que a la vez remite de manera inmediata a toda la humanidad. En la universalidad de los derechos del Otro cada uno permanece Infinito, pues se trata de una "incomparable unicidad en la que el género común se desvanece y en la que los individuos dejan precisamente de ser intercambiables como la moneda" (Lévinas, 1987, p. 161).

La mejor expresión del fundamento de los derechos humanos quizás haya sido acuñada por Emmanuel Kant en la segunda formulación del imperativo categórico: "obra de tal modo que uses la humanidad tanto en tu persona como en la persona de cualquier otro siempre a la vez como fin, nunca sólo como medio" (Kant, 1785, p. 188). Lévinas reconoce que si la voluntad fuese completamente racional, este imperativo categórico sería "el principio último del derecho humano" (Lévinas, 1985, p. 217). No obstante, sin dejar de reconocer lo importante que es "preservar al hombre de una dependencia en la que él no sería más que un mero medio para una finalidad de la que él no sería en ningún caso el fin" (Lévinas, 1985, p. 215), el pensamiento del lituano-francés señala otra dirección.

La afirmación fenomenológica que hace Lévinas de los derechos del Otro se basa en el rostro mismo de ese Otro. Apartándose del 
racionalismo kantiano de cuño metafísico que afirma el ser en la autonomía, Lévinas señala como principio de los derechos del Otro hacia el "des-inter-esamiento de la bondad: otro en su demanda, que es una orden, otro como rostro, otro que «me mira»" (Lévinas, 1985, p. 218). Se trata de un acontecimiento ético que impone al yo la consagración al Otro, en la anulación de la propia libertad. "Todo sucede como si yo estuviese siempre en el comienzo; excepto en la proximidad del prójimo. Soy requerido para una responsabilidad jamás contraída, inscrita en el rostro del Otro. Nada hay más pasivo que esta exposición anterior a toda libertad" (Lévinas, 1968, p. 69).

Desde la perspectiva levinasiana se hace evidente que el principio y fundamento de los derechos humanos está en el rostro de quien sufre. Se trata de los derechos de un Otro que tiene palabra, y cuya palabra es grito que clama justicia. El rostro y el grito de cada persona que ve conculcados sus derechos son el rostro y el grito de toda la humanidad. Por eso, ante la aparición del rostro, que es epifanía, la violencia del mundo y de la historia se interrumpe. La afirmación del ser cesa ante la epifanía del rostro del Otro

La violencia se extiende por el mundo como fuerza y empeño por ser, "el ser, en esta libertad, es así entendido por él mismo como la fuerza y el esfuerzo por ser... El hombre moderno persiste en su ser soberano preocupado únicamente por asegurar los poderes de su soberanía" (Lévinas, 1998, p. 74). Pero desde la óptica levinasiana, la libertad estrechamente ligada a la doctrina tradicional de los derechos humanos, y primera expresión suya, queda suspendida en el pensamiento como condición de una responsabilidad que interrumpe la afirmación del ser.

La dinámica afirmativa del ser se ve interrumpida en la propia vida cuando ante la mirada del yo se presenta el rostro del Otro, como una luz que todo lo ilumina y que deja ver la imposibilidad de renunciar a la custodia de los derechos humanos universales como derechos del Otro. Para Lévinas, los derechos de todo Otro son universales, pero tal universalidad se fundamenta en la diferencia del Otro y en la pasividad del yo. La suspensión de la propia libertad y de la renuncia a la identidad ontológica entre los seres humanos abre espacio a la illeidad de todo Otro, que posibilita otro modo que el ser: el modo de la responsabilidad.

\section{Referencias}

Kant, E. (1785 / 1996). Grundlegung zur Metaphysik der Sitten. Barcelona: Ariel.

Lévinas, E. (1974 / 2006). Autrement qu'être ou au-delà de l'essence. Paris: Librairie Genérale Française. Kluwer Academic.

Lévinas, E. (1947 / 2004). De l'existence à l'existant. Paris: Librairie Philosophique J. Vrin.

Lévinas, E. (1985 / 2007). "Droits de l'Homme et bonne volonté". Dans: Entre nous. Essais sur le penser-à-l'autre. Paris: Librairie Genérale Française. Grasset.

Lévinas, E. (1987). Hors sujet. Paris: Libraire Genérale Française. Fata Morgana.

Lévinas, E. (1961 / 1990). Totalité et infini Essai sur l'exteriorité. Paris: Librairie Genérale Française. Kluwer Academic.

Lévinas, E. (1934/ 1997). Quelques réflexions sur la philosophie de l'hitlérisme. Paris: Éditions Payot \& Rivages.

Lévinas, E. (1998). Éthique comme philosophie première. Paris: Éditions Payot $\&$ Rivages.

Lévinas, E. (1930 / 2001). Théorie de l'intuition dans la phénoménologie de Husserl. Paris: Librairie Philosophique J. Vrin. 
Lévinas, E. (1968 / 2007). Un Dieu homme?.

Dans: Entre nous. Essais sur le penserà-l'autre. Paris: Librairie Genérale Française. Grasset.

López, E. (2002). La crítica a la metafísica en Nietzsche. En La postmodernidad a debate. Biblioteca Colombiana de Filosofía No. 19. Bogotá: Universidad Santo Tomás.

López, E. (2005). De la autonomía a la pasividad. Reflexiones en torno al sujeto moral. Bogotá: Pontificia Universidad Javeriana. Facultad de Teología.
Purcell, M. (1996). The ethical significance of illeity (Emmanuel Lévinas). In The Heytrop Journal, 2(37). Oxford: Blackwell Publishers.

Sucasas, A. (1998). Autopercepción intelectual de un proceso histórico. En Emmanuel Lévinas. Un compromiso con la Otredad. Pensamiento ético de la intersubjetividad. Revista Anthropos. Huellas del conocimiento, 176. Barcelona:

Sucasas, A. (2004). Emmanuel Lévinas (1906-1995): el absoluto ético. En Un libro de huellas. Aproximaciones al pensamiento de Emmanuel Lévinas. Madrid: Trotta. 